\begin{tabular}{l} 
İŞLETME ARAŞTIRMALARI DERGİSI \\
JOURNAL OF BUSINESS RESEARCH-TURK \\
2021, 13(4), 2976-2989 \\
https://doi.org/10.20491/isarder.2021.1302 \\
\hline
\end{tabular}

\title{
Lojistik Faaliyetlerde Antrepoların Etkinliğinin Veri Zarflama Analizi ile Belirlenmesi (Determining the Efficiency of Entrepots in Logistics Activities by Data Envelopment Analysis)
}

Aynur ACER iD a

a İstanbul Arel Üniversitesi, İktisadi ve İdari Bilimler Fakültesi, Lojistik Yönetimi Bölümü, İstanbul, Türkiye. aynuracer@arel.edu.tr

\begin{tabular}{|c|c|}
\hline MAKALE BİLGİSI & ÖZET \\
\hline Anahtar Kelimeler: & Amaç - Lojistik faaliyetlerde uluslararası ticaret, ithalat \\
\hline Antrepo & antrepolar ara noktalar olarak önemli rol üstlenmektedir. Antrepoların performanslarının \\
\hline Veri Zarflama Analizi (VZA) & değerlendirilmesinde etkinlik ve verimlilik kavramları önemlidir. Her işletme bir önceki yıldan daha \\
\hline Etkinlik & farklı ve iyi hedeflere ulaşmak için sahip olduğu kaynakları en optimal bir şekilde kullanmayı talep eder. \\
\hline Lojistik Faaliyet & $\mathrm{Bu}$ çalışma öncelikle antrepoların etkinliğinin değerlendirilmesinde kullanılan nicel kriterlerin neler \\
\hline $\begin{array}{l}\text { Çok Kriterli Karar Verme } \\
\text { (ÇKKV) }\end{array}$ & $\begin{array}{l}\text { olduğunun belirlenmesini ve bu kriterlere göre antrepoların etkinliğinin değerlendirilmesini } \\
\text { amaçlamaktadır. }\end{array}$ \\
\hline
\end{tabular}

Yöntem - Çalışmada antrepoların etkinliğinin değerlendirilmesinde literatürde yaygın olarak kullanılan ve kullanışlı bir teknik olan Veri Zarflama Analizi (VZA) kullanılmıştır. Veri zarflama analizinin yöntem olarak tercih edilmesinin nedeni ise, bu yöntem diğer çok kriterli karar verme yöntemlerinden gibi sadece Gönderilme Tarihi 19 Şubat alternatifleri performansa göre sıralamakla kalmaz, aynı zamanda etkin olmayan alternatifler için 2021 önerilerde bulunur. Uzman görüşleri ışığında kriter olarak antrepo alanı, çalışan sayısı, forklift sayısı, Revizyon Tarihi 9 Ekim 2021

Kabul Tarihi 15 Ekim 2021 transpalet sayısı, beyanname sayısı, tır/konteyner sayısı, elleçlenen eşya miktarı ve antrepoya kabul edilen eşya miktarı ölçütleri değerlendirme kriterleri olarak kullanılmıştır. 2019 yılı verilerinin kullanıldığı çalışmada bu veriler 01 Şubat 2020 ve 01 Temmuz 2020 aralığında antrepolardan yüzyüze ve mail olarak talep edilmiştir.

Makale Kategorisi:

Araştırma Makalesi

Bulgular - İlk olarak 2019 yılı verilerinin elde edildiği 35 antreponun etkinliği, girdi yönelimli CCR ve BCC yöntemleriyle analiz edilmiştir. Sonrasında ise homojen özelliğe sahip antrepoları tespit etmek için kümeleme analizi yönteminden hiyerarşik kümeleme tekniği kullanılmış ve 31 antreponun homojen olduğu tespit edilmiştir. Son adımda da bu 31 antrepo için girdi yönelimli VZA-CCR ve BCC yöntemleri kullanılarak etkinlikleri yeniden değerlendirilmiştir. Her iki analiz sonucunda da antrepo 7, 9, 10, 15, 17, $18,20,23,24,25,28,31,32,33,34$ ve 35'in göreli etkin antrepolar olduğu tespit edilmiştir. VZA analiz sonucunda etkin olan ve etkinsiz antrepolar tespit edilerek, etkin olmayan antrepolar için önerilerde bulunulmuştur.

Tartışma - Çalışmada antrepo alanı, çalışan sayısı, forklift sayısı, transpalet sayısı, beyanname sayısı, tır/konteyner sayısı, elleçlenen eşya miktarı ve antrepoya kabul edilen eşya miktarı gibi antrepoların etkinliğinin değerlendirilmesinde kullanılan nicel kriterlerin her biri; operasyonel etkinliğinin belirlenmesinde önemli rol oynamaktadır.

\begin{tabular}{|c|c|c|}
\hline \multicolumn{2}{|l|}{ ARTICLE INFO } & ABSTRACT \\
\hline \multicolumn{2}{|l|}{ Keywords: } & Purpose - Entrepots play a considerable role as intermediate points in the realization of international \\
\hline & , import and export transactions in logistics activities. The concepts of efficiency and productivity \\
\hline $\begin{array}{l}\text { Data Envelopment } \\
\text { (DEA) } \\
\text { Efficiency } \\
\text { Logistics Activities }\end{array}$ & & $\begin{array}{l}\text { come to the fore when evaluating the performance of entrepots. Every business demands to use its } \\
\text { resources in the most optimal way to achieve different and better goals than the previous year. This study } \\
\text { primarily aims to determine the quantitative criteria used to evaluate the efficiency of entrepots and to } \\
\text { evaluation the bonded warehouses according to these criteria. }\end{array}$ \\
\hline Multi Criteria & Decision & Design/methodology/approach - Data Envelopment Analysis (DEA), which is a useful and widely used \\
\hline \multicolumn{2}{|l|}{ Making (MCDM) } & $\begin{array}{l}\text { technique in the literature, was used to evaluate the efficiency of entrepots in the study. The reason why } \\
\text { data envelopment analysis is preferred as a method is that this method, like other multi-criteria decision- } \\
\text { making methods, not only ranks the alternatives according to performance, but also makes suggestions }\end{array}$ \\
\hline \multicolumn{2}{|c|}{ Received 19 February 2021} & $\begin{array}{l}\text { for inefficiency alternatives. Determined in the light of expert opinions, the criteria of bonded warehouse } \\
\text { area, the number of employees, the number of forklifts, the number of pallet trucks, the number of }\end{array}$ \\
\hline
\end{tabular}

\section{Önerilen Atıf/ Suggested Citation}

Acer, A. (2021). Lojistik Faaliyetlerde Antrepoların Etkinliğinin Veri Zarflama Analizi ile Belirlenmesi, İşletme Araştırmaları Dergisi, 13 (4), 2976-2989. 
Revised 9 October 2021

Accepted 15 October 2021

Article Classification:

Research Article declarations, the number of trucks / containers, the amount of handling freight and the amount of goods accepted were used as evaluation criteria in the study. In the study using the data of 2019, these data were requested from the entrepots face to face and by mail between 01 February 2020 and 01 July 2020.

Findings - Firstly, the efficiency of 35 entrepot, from which 2019 data were obtained, was analyzed with input-oriented DEA-CCR and BCC methods. Afterwards, hierarchical clustering technique, which is one of the clustering analysis method, was used to identify warehouses with homogeneous characteristics and it was determined that 31 entrepots were homogeneous. In the last step, their efficiency was reevaluated for these 31 entrepots using input-oriented DEA-CCR and BCC methods. As a result of both analyzes, entrepot 7, 9, 10, 15, 17, 18, 20, 23, 24, 25, 28, 31, 32, 33, 34 and 35 were found to be relatively efficiency. As a result of DEA analysis, efficiency and inefficiency entrepots were determined and suggestions were made for inefficiency entrepots.

Discussion - Each of the quantitative criteria used in the evaluation of the efficiency of entrepots, such as the warehouse area, the number of employees, the number of forklifts, the number of pallet trucks, the number of declarations, the number of trucks / containers, the amount of handling freight and the amount of goods accepted into entrepots plays an important role in determining the operational efficiency of entrepots.

\section{GİRIŞ}

Ürünlerini müşterilerine sunmak ve müşteri ihtiyaçlarını karşılamak isteyen tüm kuruluşlarda mal veya malzeme hareketliliği söz konusudur. Bir organizasyonun merkezinde, ürünleri yaratan ve teslim eden operasyonlar yatmaktadır. Üreticiler, tedarikçilerden hammadde toplayan ve bitmiş ürünleri müşterilere teslim eden fabrikalar kurarken, perekende mağazaları toptancılardan düzenli teslimatlar alır. Tüm bu hareketlerde ön plana çıan lojistik, söz konusu eşya veya malzemelerin tedarikçiler ve müşteriler arasındaki yolculuğunda taşınmasından ve depolanmasından sorumludur. Lojistik, tedarikçilerden üreticilere, organizasyon içindeki operasyonlar yoluyla ve daha sonra müşterilere giden malzeme veya materyallerin akışından sorumlu bir işlevdir (Waters, 2003:4-5). Lojistiğin en geniş tanımı Tedarik Zinciri Yönetimi Profesyonelleri (CSCMP) tarafından yapılmıştır. Bu tanıma göre lojistik "müşterilerin ihtiyaçlarını karşılamak üzere ürünlerin üretildiği noktadan, tüketim noktasına kadar olan tedarik zinciri içindeki servis hizmetlerinin malzemelerin ve bilgi akışının etkin ve verimli bir şekilde çift yöne doğru hareketinin depolanması, planlanması, uygulanması ve kontrol edilmesi süreci" olarak ifade edilmektedir. Günümüzde işletmeler hem maliyetlerini düşürmek hem de müşteri memnuniyetini arttırmak için lojistik faaliyetlere önem vermektedir. Doğru ürünün, doğru miktarda, doğru zamanda, doğru şartlarda, doğru yerde, doğru maliyette, doğru kişiye ulaştırılmasını sağlayan lojistik (Shapiro \& Heskett, 1985: 6) bir dizi faaliyeti içermektedir. Bu faaliyetler arasında taşıma, depolama, müşteri hizmetleri, talep tahmini ve planlama, elleçleme ve paketleme, envanter yönetimi, bilgi yönetimi ve sipariş süreci, satın alma ve tedarik, tersine lojistik, gümrükleme ve sigortalama vb. yer amaktadır.

Lojistik faaliyetler içinde önemli bir destek faaliyet olan gümrükleme hizmetlerinde antrepolar önemli görev üstlenmektedir. Dış ticarette ve lojistik sektöründe yaşanan gelişmelere paralel olarak ticari eşyaların muhafaza edildiği yerler olan antrepoların fiziksel dağıtım içindeki önemi ve gelişimi günden güne arttırmaktadır. İthalat, ihracat ve gümrükleme süreçlerinde görev alan antrepolar, eşyaların depolandığı ve taşımaya hazır hale getirildiği açık veya kapalı alanlar olabilir. Sipariş ve bilgi işleme, elleçleme, stok yönetimi, gümrükleme, siğortalama, müşteri hizmetleri ve koruyucu ambalajlama gibi hizmetlerin verildiği antrepolar 4458 sayılı Gümrük Kanunu ve Gümrük Yönetmeliği'nde belirtilen özellikleri taşıyan ve gümrüklü sahalarda kurulan yerleri ifade etmektedir. 4458 sayılı Gümrük Kanunu ve Gümrük Yönetmeliği'ne göre eşyaların antrepoda miktar, kalite ve özellikleri incelenerek nitelik veya nicelik açısından kıymet tespitleri yapılır ve uygun şartlarda korunmaları gerçekleştirilir.

Antrepolar, Avrupa Birliği kanununda "topluluk üyesi ülkelerde gümrük idarelerinin uygun gördügü koşullarda ve yerlerde açllan, gümrüğün gözetimi ve denetimi altında olan yerler" olarak tanımlanmaktadır (Arlı, 2009:39). Bir ülkenin siyasi sınırları içinde yer alan ancak gümrük sınırları dışında özellikli yerler olan antrepolar bir nevi depolama işlevi sunmaktadır. Bu nedenle bir eşyanın antrepoda depolandığı süreç içinde gümrük vergisi alınmamakta, malların ithalatı için gümrük idarelerine müracat edildiği taktirde mali yükümlülükler yerine getirilmektedir (Koban ve Keser, 2007:153). Tanyaş ve Başkak (2012) antrepoların kullanım amaçlarını şu şekilde 


\section{A. Acer 13/4 (2021) 2976-2989}

sıralamıştır: (1) İşletmelerin vergileri ertelemek amacıyla kullanımı, (2) Ürünün ayniyetini muhafaza ederek imalat, ön/son montaj, bakım, onarım, koruyucu ambalajlama, sıralama ve yük bölme gibi basit işlemlere tabi tutulması, (3) Transit amaçlı kullanım.

Gümrük Yönetmeliğinin 328. maddesinde antrepolar herkesin eşyasının konulabildiği "genel antrepolar (A, B ve F tipi)" ve sadece antrepo işleticisine ait eşyaların konulabildiği "özel antrepolar (C, D ve E)" olmak üzere iki sınıfa ayrılmıştır. Yine 329. madde bu çalışmada uygulama alanı bulan A tipi antrepo da tanımlanmıştır. Bu tanıma göre "işleticisinin, stok kayıtlarını tuttuğu ve antrepoya konulan eşyada bir noksanlık olması halinde gümrük vergilerini ödemekten yükümlü olduğu genel antrepo türü" dür ve tüm sorumluluk antrepo işleticisine verilmiştir. Türkiye'de faaliyet gösteren antrepo türleri ve sayıları bölge müdürlüklerine göre sınıflandırılmış ve aşağıda Tablo 1.' de verilmiştir.

Tablo 1. 2018 Yılı Faaliyet Gösteren Antrepo Türleri ve Sayıları

\begin{tabular}{|c|c|c|c|c|c|}
\hline & Antrepo Türleri & 2015 & 2016 & 2017 & 2018 \\
\hline \multirow{3}{*}{$\begin{array}{c}\text { Genel } \\
\text { Antrepo }\end{array}$} & A TİPİ & 600 & 601 & 603 & 580 \\
\hline & В TïPİ & 3 & 2 & 1 & 1 \\
\hline & F Tïİ & 2 & 2 & 2 & 2 \\
\hline \multirow{5}{*}{$\begin{array}{c}\text { Özel } \\
\text { Antrepo }\end{array}$} & Genel Antrepo Toplamı & 605 & 605 & 606 & 583 \\
\hline & C TİPİ & 445 & 429 & 375 & 372 \\
\hline & C TİPİ (Gümrüksüz Satış Mağazaları) & 174 & 175 & 175 & 175 \\
\hline & D TİPI & 0 & 0 & 0 & 0 \\
\hline & E Tїї & 7 & 4 & 3 & 4 \\
\hline \multicolumn{2}{|r|}{ Özel Antrepo Toplamı } & 626 & 608 & 553 & 551 \\
\hline \multicolumn{2}{|r|}{ Genel Toplam } & 1231 & 1213 & 1159 & 1134 \\
\hline
\end{tabular}

Kaynak: Ticaret Bakanlığı Verileri, https://www.ticaret.gov.tr/, (12.01.2021)

Tablo 1. incelendiğinde Türkiye'de hizmet veren antrepo sayılarında 2015 yılından 2018 yılına doğru genel olarak bir azalma olduğu gözlenmektedir. Örneğin 2015 yılında toplam sayıları 600 olan A tipi antrepolar 2018 yılında 580'e düşmüştür. Bu antrepolardan 189'u İstanbul'da farklı bölge müdürlüklerine bağlı olarak hizmet vermektedir. Muratbey gümrük müdürlüğü de bunlardan birisidir ve bu müdürlüğe bağlı 60 civarında A tipi antrepo olduğu bilgisi elde edinilmiştir. Dolayısıyla bu çalışmada en önemli bölge müdürlüklerinden biri olan Muratbey Gümrük Müdürlüğü'ne bağlı 35 antreponun operasyonel etkinliği 2019 yılı için kriterleri temel alınarak Veri Zarflama Analizi (VZA) yöntemiyle değerlendirilmeye tabi tutulmuştur.

\section{LITERATÜR TARAMASI}

Bu bölümde doğrusal proglamlamanın özel bir türü olan ve göreceli etkinlik ölçümünde yaygın olarak kullanılan yöntemlerden biri olan VZA yöntemiyle ilgili literatürde yapılan çalışmalara yer verilmiştir. VZA ile ilgili ilk çalışma Farrel (1957) tarafından yapılmış ve çalışmada aynı amaçlara sahip olan işletmelerin etkinliği ölçülmüştür. VZA yöntemi yıllar içinde farklı alanlarda faaliyet gösteren kurumların göreceli etkinliğinin değerlendirilmesinde uygulama alanı bulmuştur. Örneğin hastaneler (Jacobs, 2001: Tetik, 2003: Nayar ve Özcan, 2008: Gülsevin ve 
Türkan, 2012: Torabipour vd., 2014: Kohl vd., 2019), bankalar (Thanassoulis, 1999: Seyrek ve Ata, 2010: Behdioğlu ve Özcan, 2009: Budak, 2011: Paradi ve Zhu, 2013: Henriques vd., 2018), işletmeler (Ulucan, 2002: Düzakın ve Düzakın, 2007. Chen vd., 2008: Zhang vd., 2016), üniversiteler (Sarrico \& Hogan, 1997: Abbot \& Doucouliagos, 2003: Özden, 2008: Kutlar ve Kartal, 2004: Baysal vd., 2005: Bal, 2013), mahkemeler (Yeung \& Azevedo, 2011: Santos \&Amado, 2014) gibi kurumların etkinliklerinin değerlendirilmesinde yöntem olarak veri zarflama analizi kullanılmıştır. Literatürde lojistik alanında VZA ile ilgili yapılan çalışmalardan bazıları şunlardır:

19 OECD ülkesinin demiryollarının etkinliğini 1978-89 dönemleri için değerlendirmeye tabi tutan Oum ve Yu (1994) çalışmasında girdi değişkenleri olarak çalışan sayısı, tüketilen enerji miktarı, hat uzunluğu, yolcu/yük taşıyan vagol sayısı ve lokomotif sayısını, çıktı değişkeni olarak da toplam yolcu-km, toplam ton-km uzunlukları ve gelir ölçütünü kullanmıştır.

Easton vd. (2002) satın alma yöneticilerinin işlemlerinin verimliliğini arttırmalarına yardımcı olmak amacıyla, petrol endüstrisindeki firmaların satın alma performanslarını VZA ile değerlendirmiştir. Çalışmada operasyon giderleri, profesyonellik, yönetim ve aktif tedarikçi ölçütleri girdi değişkenini oluşturmaktadır.

Min ve Joo (2006) çalışmasında 3pl olarak faaliyet gösteren lojistik firmalarının etkinliklerini faaliyet geliri, alacak hesabı, maaş ve ücretler, faaliyet giderleri ve maddi varlıklar ölçütlerini temel alarak VZA ile değerlendirmeye tabi tutmuştur.

Tonanont vd. (2008) çalışmasında elektronik sektöründe hizmet veren firmaların tersine lojistik performansını Balans Skor Kartları, Analitik Hiyerarşi Süreci (AHS) ve VZA ile değerlendirmeye tabi tutmuştur.

Macaristan lojistik merkezlerinin etkinliğini değerlendirdiği çalı̧̧masında Markovits-Somogyi vd. (2011) VZA yöntemini kullanmıştır. Girdi olarak ofislerin alanı, çalışan sayısı, kullanılabilir depolama alanı değişkenlerini; çıktı olarak da toplam satış geliri hacmi ve elleçlenen yük miktarı değişkenleri kullanılarak 26 lojistik merkezini analiz etmiştir.

Perçin ve Çakır (2012) çalışmasında TCDD'nin 1975-2010 yılları arasındaki performanslarını VZA ile ölçmüşlerdir. Çalışmada girdi değişkenleri olarak yolcu araç kapasitesi, yük taşıma kapasitesi ve çalışan sayısı; çıktı değişkenleri olarak da yolcu-km ve net ton-km ölçütleri kullanılmış ve TCDD'nin en etkin döneminin 2010 yılı olduğu sonucu elde edilmiştir.

Önsoy (2013) çalışmasında personel sayısı, şube sayısı ve araç sayısı değişkenlerini girdi değişkeni, müşteri sayısını ise çıktı değişkeni olarak kullanmış ve 5 kargo şirketinin performansını VZA yöntemi ile belirlemiştir.

Demirci ve Tarhan (2017) çalışmasında Mersin ilinde karayolu taşımacılığı alanında faaliyet gösteren 25 firmanın etkinliğini VZA yöntemiyle değerlendirmiştir. Marş çalıştırma süresi, destek personel miktarı, bakım onarım masrafı ve yakıt sarfiyatı ölçütleri girdi değişkenleri olarak kullanılırken, sefer sayısı ve araç başına aylık katedilen mesafe ölçütleri çıktı değişkeni olarak kullanılmıştır.

Petekkaya (2018) çalışmasında Türkiye'de faaliyet gösteren 18 serbest bölgenin etkinliğini VZA yöntemiyle tespit etmiştir. Girdi olarak istihdam ve yüzölçümü değişkenleri, çıktı olarak da ticaret hacmi değişkeni çalışmada temel alınmıştır.

Yıldırım ve Ayvaz (2019) tarafından yapılan çalışmada 15 ülkenin lojistik performansları 2016 yılı verileri temel alınarak değerlendirilmeye tabi tutulmuştur. Gümrük prosedürleri, altyapı ve enerji kullanım değişkenleri girdi değişkenleri olarak, karbondioksit emisyonu, lojistik hizmet kalitesi ve iş gücü oranı ise çıktı değişkenleri olarak kullanılarak etkin ve etkinsiz ülkeler belirlenmiştir.

Bayat ve Özdemir (2019) çalışmasında 2015 yılı için karayolu uzunluğu, demiryolu uzunluğu, limanlara uğrayan gemi sayısı, uçak iniş-kalkış sayıları, gayrisafi yurtiçi hâsıla ve taşıt sayısını girdi değişkenleri; lojistik sektöründe faaliyet yürüten işletmelerin cirolarını da çıktı değişkeni olarak kullanmış ve istatistik bölge birimleri düzey 2'de yer alan bölgeleri değerlendirmeye tabi tutmuştur. Analiz sonucunda TR10, TR33, TR42, TR51 ve TR90 bölgelerinin etkin olduğu bulgusu elde edilmiştir. 


\section{A. Acer 13/4 (2021) 2976-2989}

Ersoy ve Tehci (2020) çalışmasında Türkiye'de lojistik sektöründe faaliyet gösteren ve Fortune 500 listesinde yer alan 9 işletmenin performansını değerlendirmeye tabi tutmuştur. Çalışmada 2016 ve 2017 yılına göre çalışan sayısı ve toplam aktifler girdi değişkeni, net satışlar ve ihracat miktarı ise çıktı değişkeni olarak kullanılmıştır.

Ustalı ve Tosun (2020) çalışmasında G-20 ülkelerinin 2007-2016 yılı lojistik performanslarını VZA ve Malmquist Toplam Faktör Verimliliği ile analize tabi tutmuştur. Çalışma sonucunda en verimli dönemin 2007-2010 dönemi olduğu tespit edilmiştir.

Lojistik alanında VZA ile ilgili yapılan çalışmalar yukarıda da belirtildiği gibi daha çok taşıyıcı firma seçimi ve lojistik firmaların performansının değerlendirmesine yöneliktir. Bu nedenle bu çalışma, lojistik faaliyetlerde önemli bir destek hizmet sunan antrepoların etkinliğinin değerlendirilmesine yönelik ölçütlerin belirlenmesine katkıda bulunmayı amaçlamaktadır.

\section{YÖNTEM}

Rekabetin hızla arttığı günümüz dünyasında farklı sektörlerde faaliyet gösteren işletmelerin başarılarının değerlendirilmesinde etkinlik ölçümü önemli bir göstergedir. Belirli bir zaman dilimi içinde çeşitli faliyetleri yürütmede kullanılan girdilerin hedeflenen sayı ve kalitede çıtılara dönüştürülmesi (Sarı, 2010.20) olarak tanımlanan etkinlik, temelde işletmelerin gerçekleştirmeyi hedefledikleri ile elde ettikleri arasında kıyaslama yapmalarına imkan tanımaktadır. Bu nedenle literatürde işletmelerin etkinlik ölçümü ile ilgili parametrik (Stokastık Sınır Yaklaşımı, Serbest Dağılım Yaklaşımı ve Kalın Sınır Yaklaşımı) ve parametrik olmayan (VZA, Serbest Düzenleme Zarf Analizi) farklı yöntemler kullanılmaktadır. Doğrusal programlamanın özel bir türü olan veri zarflama analizi de yaygın kullanılan bu yöntemlerden birisidir.

Birbirine benzer birimlerin etkinliğini ölçmede kullanılan matematiksel bir programlama tekniği (Ramanathan, 2003) olan VZA, çok az varsayım gerektirmektedir. VZA, birden fazla girdiyi birden fazla çıktıya dönüştürerek, karar verme birimleri (KVB) olarak tanımlanan bir dizi alternatifin performansını değerlendirmede kullanılan bir yaklaşımdır (Cooper vd.,2011:2). Veri zarflama analizi aynı zamanda çıtıların ağırlıklı toplamlarını girdilerin ağırlıklı toplamlarına bölerek her bir KVB'nin etkinliğini ölçmede kullanılan matematiksel bir yöntemdir (Jablonsky, 2016:37). Dolayısıyla herhangi bir KVB'nin etkin olmama miktarı veya kaynakları VZA ile belirlenebilir. Ayrıca yöntem etkin olmayan birimlere referans kümeleri sunmakta ve girdilerde meydana gelen bir artış veya azalışın çıktı miktarına etkilerini gösterebilmektedir (Behdioğlu ve Özcan, 2009:3).

VZA ile ilgili farklı modeler mevcuttur. Farrel (1957)'in etkin sınır çalışmasını referans alarak 1978 yılında Charnes, Cooper ve Rhodes, VZA-CCR modelini geliştirmiştir. Bu model ölçeğe göre sabit getiri varsayımı altında analiz yapmaktadır. 1984 yılında Banker, Charnes ve Cooper tarafından ölçege göre değişken getiri varsayımı altında çalışan, teknik etkinlik ve ölçek etkinliğini dikkate alan VZA-BCC modeli öne sürülmüştür (Cooper vd., 2011:4). Bir diğer model de Charnes, Cooper, Golany, Seiford ve Stutz tarafından geliştirilen toplamsal modeldir. Bu modelde girdi veya çıktı ayrımı yapılmadan her iki durum da bir arada dikkate alınmakta ve girdi fazlalığı ve çıktı eksikliği aynı anda değerlendirilmektedir (Savaş, 2015:2016).

Yukarıda da belirtildiği gibi VZA ile ilgili geçmişten günümüze farklı modeller geliştirilmiştir. Bu geliştirilen modeler arasında yaygın olarak kullanılanları ise ölçeğe göre sabit veya değişken getiri varsayımı altında girdi ve çıktıya yönelik analiz eden CCR ve BCC modelleridir. Hangi modeller tercih edilirse edilsin VZA ile etkinlik analizinin uygulama aşamaları şu şekilde sıralanmaktadır: (1) KVB'lerin belirlenmesi, (2) Girdi ve çıtıların belirlenmesi, (3) VZA modelinin uygulanması, (4) Etkinlik değerlerinin elde edilmesi, (5) Referans kümelerin oluşturulması, (6) Etkin olmayan karar birimleri için hedef belirleme, (7) Sonuçların değerlendirilmesi ve yorumlanması.

Veri zarflama analizinde model seçimi yapılırken karar vericinin girdi üzerinde denetimi varsa girdiye yönelik modeler, çıtı üzerinde denetimi varsa çıktıya yönelik modeler seçilir (Çağlar, 2012:155). Girdiye yönelik modeller operasyonel ve yönetimsel durumların analizinde kullanılırken, planlama ve strateji analizlerinde daha çok çıktı

yönelimli modeller tercih edilmektedir (Wang vd., 2003). Bu nedenle bu çalışmada antrepoların operasyonel 
etkinliğinin değerlendirilmesinde girdi yönelimli VZA modelleri kullanılmıştır ve kullanılan modeller aşağıda belirtilmiştir.

\section{Girdi Yönelimli CCR Modeli}

Her biri m girdi ve s çıtıya sahip n adet karar verme birimlerinin (KVB) olduğu varsayıldığında, karar verme birimlerinin göreceli etkinlikleri Charnes vd. (1978) tarafından önerilen aşağıdaki model yardımıyla elde edilmektedir (Cooper vd. 2011: 11).

$$
\begin{aligned}
& \text { Amaç Fonksiyonu; } \quad \min \theta-\varepsilon \sum_{i=1}^{m} s_{i}^{-}+\sum_{r=1}^{s} s_{r}{ }^{+} \\
& \text {Kisitlar; } \quad \sum_{j=1}^{n} x_{i j} \lambda_{j}+s_{i}^{-}=\theta x_{i o} \quad \mathrm{i}=01,2, \ldots, \mathrm{m} \\
& \sum_{j=1}^{n} y_{r j} \lambda_{j}-s_{r}^{+}=y_{r 0} \quad \mathrm{r}=1,2, \ldots ., \mathrm{s} \\
& \lambda_{j}, s_{i}^{+}, s_{i}^{-} \geq 0 \quad \mathrm{j}=1,2, \ldots . \mathrm{n} .
\end{aligned}
$$

Doğrusal olmayan kesikli matematiksel modelin basit bir dönüşüm kullanılarak dogrusal programlama modeline dönüştürülmesiyle elde edilen bu modelin çarpım formu aşağıda gösterilmiştir (Cook ve Zhu, 2006: 6).

$$
\begin{array}{ll}
\text { Amaç Fonksiyonu; } \quad & \max z=\sum_{r=1}^{s} \mu_{r} y_{r 0} \\
& \sum_{r=1}^{s} \mu_{r} y_{r j}-\sum_{i=1}^{m} v_{i} x_{i j} \leq 0 \\
& \sum_{i=1}^{m} v_{i} X_{i 0}=1 \\
& \mu_{r}, v_{i} \geq \varepsilon>0
\end{array}
$$

\section{Girdi Yönelimli BCC Modeli}

BCC modeli ölçeğe göre değişken getiri altında her bir karar verme için teknik etkinliği ölçen girdi ve çıktı yönelimli modellerden oluşmaktadır (Göktolga ve Artut, 2014:58). Bu çalışma operasyonel etkinliğin ölçülmesini amaçladığı için aşağıda girdi odaklı BCC modelinin matematiksel gösterimi belirtilmiştir (Banker vd., 2011):

$$
\begin{array}{ll}
\operatorname{Min}_{0}-\varepsilon\left(\sum_{i=1}^{m} s_{i}^{-}+\sum_{r=1}^{s} s_{r}^{+}\right. \\
\sum_{j=1}^{n} \lambda_{j} x_{i j}+s_{i}^{-}=\theta_{0} x_{i 0} & \mathrm{i}=1,2, \ldots, \mathrm{m} \\
\sum_{j=1}^{n} \lambda_{j} y_{r j}-s_{i}^{+}=y_{r 0} & \mathrm{r}=1,2, \ldots, \mathrm{s} \\
\sum_{j=1}^{n} \lambda_{i}=1 & \mathrm{j}=1,2, \ldots, \mathrm{n} \\
\lambda_{i} \geq 0 & \mathrm{j}=1,2, \ldots, \mathrm{n}
\end{array}
$$


BCC modelinin çarpan formu aşağıda yer almaktadır (Banker ve diğerleri, 1984: 1088):

$$
\begin{array}{ll}
\text { Amaç Fonksiyonu; } & \operatorname{mak} \sum_{r=1}^{s} \mu_{r} y_{r o}-\mu_{0} \\
& \sum_{r=1}^{s} \mu_{r} y_{r j}-\sum_{i=1}^{m} v_{i} x_{i j}-\mu_{0} \leq 0 \quad \mathrm{j}=1,2, \ldots, \mathrm{n} \\
& \sum_{i=1}^{m} v_{i} x_{i 0}=1 \\
& \mu_{r}, v_{i} \geq \varepsilon \quad \forall r, i
\end{array}
$$

Çalışmada yukarıda belirtilen VZA yöntemlerinin uygulanması aşamasında 2019 yılı verileri antrepo alanı, çalışan sayısı, forklift sayısı, transpalet sayısı, beyanname sayısı, tır/konteyner sayısı, elleçlenen eşya miktarı ve antrepoya kabul edilen eşya miktarı değişkenleri için antrepo işleticilerinden talep edilmiştir. Elde edilen bu veriler girdi yönelimli vza modelleri ile analize tabi tutularak sonuçları yorumlanmıştır.

\section{BULGULAR}

Ticaret Bakanlığı'nın 2018 yılı verilerine göre Türkiye' de faaliyet gösteren toplamda 1134 antrepo yer almaktadır. $\mathrm{Bu}$ antrepolardan 583 tanesi işletici ve kullanıcılarının farklı olduğu ve antrepoya alınan eşyalardan antrepo işleticisinin sorumlu tutulduğu A tipi antrepolardır. Bu antrepolardan 189'unun İstanbul'da farklı bölge müdürlüklerine bağlı olarak hizmet verdiği ve anakütleyi oluşturan 60 civarında A tipi antreponun Muratbey gümrük müdürlüğüne bağlı olarak faaliyetlerine devam ettiği bilinmektedir. İlk önce Halkalı Giriş Gümrük Müdürlüğü olarak faaliyete başlayan Muratbey Gümrük Müdürlügü günümüzde İstanbul Bölge Müdürlüğü'ne bağlı olarak faaliyet gösteren en büyük bölge gümrük müdürlüklerinden biridir. Bu müdürlüğe bağlı hizmet veren A tipi antrepo işleticileriyle mail yoluyla iletişime geçilmiş ve 35 antrepo işleticisinden istenilen kriterlerin 2019 yılı verileriyle ilgili geri dönüş sağlanmıştır. VZA yönteminde ilk yapılması gereken, karşılaştırmalı etkinlik ölçümü yapılacak olan karar verme birimlerinin seçimidir. Veri zarflama analizinde örneklemi oluşturan KVB'lerin sayısının belirlenmesiyle ilgili literatürde farklı yaklaşımlar söz konusudur. Motroi (2018) ve Boussofiane vd. (1991) çalışmalarında m girdi, $n$ çıtı sayısı olmak üzere KVB'lerin sayısının en az (m+n+1) olması gerektiğini vurgulamıştır. Dyson vd. (2001) ise etkinliği karşılaştırılacak olan KVB'lerin $2(m+n)$ 'den fazla olması gerektiğini öne sürmüştür. Bu durumda çalışmada kullanılacak KVB'lerin sayısının her iki yaklaşıma göre en az $(4+4+1)=9$ veya $2(4+4)=16$ olması gerekmektedir. Bu iki görüş temel alındığında $35 \mathrm{KVB}$ 'nin analiz ve değerlendirme için yeterli sayıda olduğu görülmektedir.

Çalışmanın uygulama kısmında gümrüklü alanlar olan ve uluslararası ticarette önemli bir transfer merkezi olarak hizmet veren antrepolardan A tipi antrepoların 2019 yılı göreli etkinlikleri girdi yönelimli VZA-CCR ve BCC modeliyle pyDEA programı kullanılarak analize tabi tutulmuştur. Yöntemde ilk yapılması gereken, karşılaştırmalı etkinlik ölçümü yapılacak karar verme birimlerinin seçimidir. Karar verme birimlerinin sayısının belirlenmesiyle alakalı farklı yaklaşımlar söz konusudur. Motroi (2018) ve Boussofiane vd. (1991) çalışmalarında m girdi, $n$ çıtı sayısı olmak üzere KVB’lerin sayısının en az $(m+n+1)$ olması gerektiğini vurgulamıştır. Dyson vd. (2001) ise etkinliği karşılaştırılacak olan KVB'lerin 2(m+n)'den fazla olması gerektiğini öne sürmüştür.

Ikinci adım ise analizde kullanılacak girdi ve çıktı değişkenlerinin belirlenmesidir. Sonuçların anlamlı olması için uygulamada seçilecek girdi ve çıtıların dikkatli tespit edilmesi gerekir. Bu aşamada antrepo işleticileri, muayene memurları ve uzman görüşlerine başvurularak literatür taraması yapılmıştır. Çalışmada, Acer ve Kalender (2020)'in antrepoların performansının değerlendirilmesiyle ilgili yapmış olduğu çalışma ve uzman görüşleri temel alınarak yapılan değerlendirmeler sonucunda antrepo alanı (I1), çalışan sayısı (I2), forklift sayısı (I3) ve transpalet 
sayısı (I4) girdi değişkenleri olarak kullanılmıştır. Beyanname sayısı (O1), tır/konteyner sayısı (O2), elleçlenen eşya miktarı (O3) ve antrepoya kabul edilen eşya miktarı (O4) ise çıtı değişkenleri olarak ele alınmıştır.

Çalışmada girdi değişkeni olarak kullanılan alan, $m^{2}$ cinsinden antrepoların sahip olduğu kapalı alanı ifade etmektedir. Çalışan sayısı, antrepo işlemlerini gerçekleştirmede en önemli girdi değişkenlerinden birisidir. Tam zamanlı çalışan, yeterli ve uzman insan kaynakları mevcudiyetidir. Operasyonel etkinliğin değerlendirilmesinde ekipmanların önemi büyüktür. Bu nedenle çalışmada hemen hemen her depo ve antrepoda bulunabilecek ekipmanlardan biri olan forklift ve transpalet sayısı diğer girdi değişkenleri olarak belirlenmiştir.

Çıktı değişkeni olarak kullanılan beyanname sayısı, eşyanın antrepoya konulması için açılması gereken antrepo beyannamesinin yıllık sayısını ifade etmektedir. Antrepoya boşaltılacak eşyalar tır ve konteynerlarla getirilmektedir. Bu nedenle bir diğer çıktı değişkeni antrepoya boşaltımı yapılan yıllık tır ve konteyner sayısıdır. Yıllık antrepoya kabul edilen eşya değişkeni verileri çalışmada kilogram $(\mathrm{kg})$ cinsinden değerlendirmeye tabi tutulmuştur. Son olarak yıllık elleçlenen eşya miktarı değişkeni, antrepolarda eşyanın ayniyetini muhafaza etmek amacıyla yapılan kap değiştirme, havalandırma gibi ek işlemleri ifade etmektedir ve kap cinsinden bu bilgiler elde edilmiştir.

Tüm bu girdi ve çıktı değişkenleri 2019 yılı için antrepo işleticilerinden yıllık olarak talep edilmiştir. 45 antrepo işleticisi ile iletişime geçilmiş ve bu işleticilerden $10^{\prime} \mathrm{u}$ bazı değişkenlere cevap vermedikleri için çalışma dişı bırakılmıştır. Bu nedenle bu çalışmada 35 KVB verileri temel alınmıştır. Değişkenler ve KVB'ler belirlendikten sonra üçüncü adım yöntemin hangi modelinin uygulanacağının belirlenmesidir. Çalışmada operasyonel etkinlik ölçülmeye çalışıldığı için girdi yönelimli CCR ve BCC modeli kullanılmıştır. KVB'lerin homojen olup olmadıklarına bakılmaksızın yapılan ilk analizde her iki modelin sonucu ve 35 KVB'nin etkinlik skoru aşağıda Tablo 2.'de verilmiştir.

Tablo 2. 35 KVB için VZA CCR ve BCC Etkinlik Sonuçları

\begin{tabular}{llllll}
\hline KVB & $\begin{array}{l}\text { CCR Etkinlik } \\
\text { Skoru }\end{array}$ & $\begin{array}{l}\text { BCC Etkinlik } \\
\text { Skoru }\end{array}$ & KVB & $\begin{array}{l}\text { CCR Etkinlik } \\
\text { Skoru }\end{array}$ & $\begin{array}{l}\text { BCC Etkinlik } \\
\text { Skoru }\end{array}$ \\
\hline Antrepo 1 & 0.8528 & 0.8655 & Antrepo 19 & 0.5974 & 0.6420 \\
Antrepo 2 & 0.149 & 1.0000 & Antrepo 20 & 1.0000 & 1.0000 \\
Antrepo 3 & 0.3643 & 0.5464 & Antrepo 21 & 0.1139 & 0.7739 \\
Antrepo 4 & 0.8812 & 0.9041 & Antrepo 22 & 0.2302 & 0.6647 \\
Antrepo 5 & 0.8539 & 1.0000 & Antrepo 23 & 1.0000 & 1.0000 \\
Antrepo 6 & 0.8435 & 0.8514 & Antrepo 24 & 1.0000 & 1.0000 \\
Antrepo 7 & 1.0000 & 1.0000 & Antrepo 25 & 1.0000 & 1.0000 \\
Antrepo 8 & 0.4744 & 0.4766 & Antrepo 26 & 1.0000 & 1.0000 \\
Antrepo 9 & 0.8556 & 0.8605 & Antrepo 27 & 1.0000 & 1.0000 \\
Antrepo 10 & 1.0000 & 1.0000 & Antrepo 28 & 1.0000 & 1.0000 \\
Antrepo 11 & 0.4887 & 0.6131 & Antrepo 29 & 0.3360 & 0.3567 \\
Antrepo 12 & 1.0000 & 1.0000 & Antrepo 30 & 0.0561 & 0.2863 \\
Antrepo 13 & 0.3954 & 0.6976 & Antrepo 31 & 1.0000 & 1.0000 \\
Antrepo 14 & 0.5164 & 0.5164 & Antrepo 32 & 1.0000 & 1.0000 \\
Antrepo 15 & 1.0000 & 1.0000 & Antrepo 33 & 1.0000 & 1.0000 \\
Antrepo 16 & 0.1076 & 0.5042 & Antrepo 34 & 1.0000 & 1.0000 \\
Antrepo 17 & 0.9516 & 1.0000 & Antrepo 35 & 1.0000 & 1.0000 \\
Antrepo 18 & 0.7906 & 0.8155 & & & \\
\hline
\end{tabular}

Tablo 2.'de BCC modelinde elde edilen etkinlik skorları, CCR modeli sonuçlarından daha olumlu çıkmıştır. Hem CCR modelinde hem de BCC modelinde etkinlik skoru 1 olan KVB'ler göreli olarak etkin antrepolardır. Dolayısıyla 7, 10, 12, 15, 20, 23, 24, 25, 26, 27, 28, 31, 32, 33, 34 ve 35 numaralı antrepolar göreli olarak etkindir. Diğerleri ise etkin olmayan antrepolardır. 
Cullinane ve Wang (2007:521), VZA'nın temelinde yatan varsayımın hem girdi hem de çıktılardaki homojenlikten kaynaklandığını ifade etmiştir. Bu nedenle analize tabi tutulacak KVB'lerin homojen olması VZA'nın en önemli özelliklerinden biridir. KVB'ler Tablo 2.'de homojen olup olmadıklarına bakılmaksızın analize tabi tutulmuştur. $\mathrm{Bu}$ aşamada çalışmada $\mathrm{KVB}^{\prime}$ yi oluşturan antrepoların homojenliği "Kümeleme Analizi" ile elde edilmeye çalışılmış ve elde edilen yeni homojen kümeyi oluşturan KVB'ler yeniden VZA analizine tabi tutulmuştur.

Kümeleme analizi, gruplanmış verileri aralarındaki benzerlikler itibariyle bir araya getiren ve benzerliklerine göre sınıflandırmada sıklıkla kullanılan çok değişkenli istatistiksel yöntemlerden biridir. Analiz sonucunda oluşan kümeler kendi içinde homojen ve kümeler arasında heterojendir. Kümeleme analizinde gözlem sayısının değişken sayısının 3-4 katı kadar olması gerektigi genel bir kanıdır (Kalaycı, 2010:349). Kümeleme analizinde kümeler arasındaki yakınlıklar ve uzaklıkların hesaplanışında farklı yöntemler söz konusudur. Bu çalışmada SPSS 21 programı yardımıyla küme sayısının araştırmacı tarafından belirlenmediği "hiyerarşik kümeleme yöntemi" ve küme içinde homojenliği, kümeler arasında heterojenliği maksimum kılan kümelerin oluşturulmasını sağlayan bir yöntem olan “Ward's Bağlantılı Kümeleme Yöntemi" ile veriler analize tabi tutulmuş ve analiz sonuçları aşağıdaki dendrogramda gösterilmiştir.

Şekil 1. Kümeleme Analizi Sonuçları
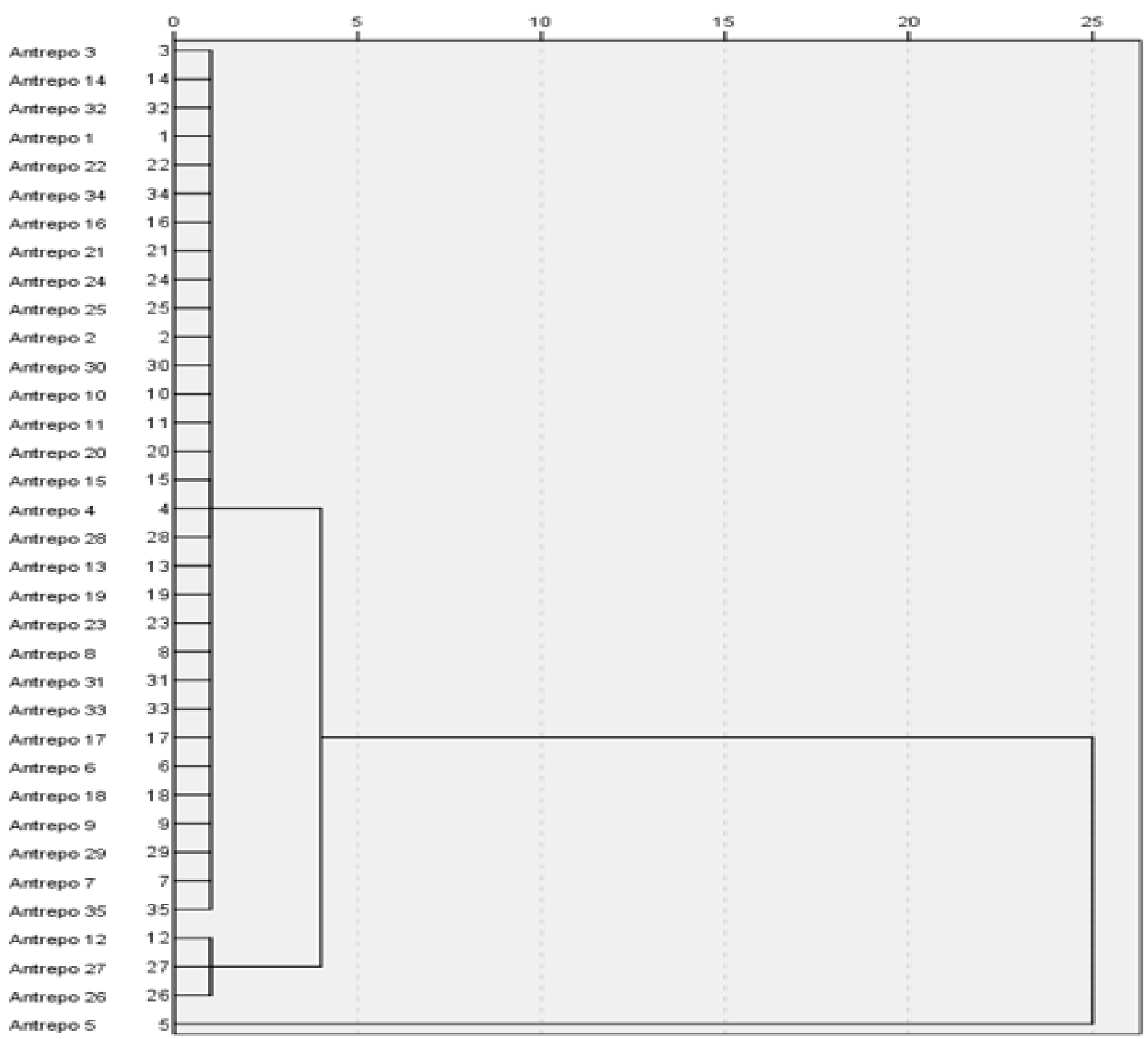
Homojen birimlerin karşılaştırılmasında VZA'nın anlamlı sonuçlar vermesi için öncelikli olarak aynı grupta olan antrepoların tespit edilmesi açısından hiyerarşik kümeleme analizi uygulanmıştır. Şekil 1.'de verilen dendrogram incelendiğinde $35 \mathrm{KVB}^{\prime}$ den Antrepo 5, 12, 26 ve 27 farklı kümelerde yer almakta ve bu antrepoların diğerleriyle homojen bir grup oluşturmadığı görülmektedir. Dolayısıyla bu dört antrepo analiz dışı bırakılarak aynı kümede yer alan 31 KVB yeniden girdi yönelikli VZA yöntemi ile analize tabi tutulmuş ve analiz sonuçları tekrardan değerlendirilmiştir.

Tablo 3. 31 KVB için VZA CCR ve BCC Etkinlik Sonuçları

\begin{tabular}{|c|c|c|c|c|c|}
\hline KVB & $\begin{array}{l}\text { CCR Etkinlik } \\
\text { Skoru }\end{array}$ & $\begin{array}{c}\text { BCC Etkinlik } \\
\text { Skoru }\end{array}$ & KVB & $\begin{array}{c}\text { CCR Etkinlik } \\
\text { Skoru }\end{array}$ & $\begin{array}{c}\text { BCC Etkinlik } \\
\text { Skoru }\end{array}$ \\
\hline Antrepo 1 & 0.852841 & 1 & Antrepo 19 & 0.601399 & 0.650979 \\
\hline Antrepo 2 & 0.263003 & 1 & Antrepo 20 & 1 & 1 \\
\hline Antrepo 3 & 0.432706 & 0.555011 & Antrepo 21 & 0.117835 & 0.773932 \\
\hline Antrepo 4 & 0.906397 & 0.910272 & Antrepo 22 & 0.249064 & 0.664767 \\
\hline Antrepo 6 & 0.969859 & 1 & Antrepo 23 & 1 & 1 \\
\hline Antrepo 7 & 1 & 1 & Antrepo 24 & 1 & 1 \\
\hline Antrepo 8 & 0.474436 & 0.47658 & Antrepo 25 & 1 & 1 \\
\hline Antrepo 9 & 1 & 1 & Antrepo 28 & 1 & 1 \\
\hline Antrepo 10 & 1 & 1 & Antrepo 29 & 0.385085 & 0.406624 \\
\hline Antrepo 11 & 0.540953 & 0.694122 & Antrepo 30 & 0.077347 & 0.286348 \\
\hline Antrepo 13 & 0.452354 & 0.698796 & Antrepo 31 & 1 & 1 \\
\hline Antrepo 14 & 0.516414 & 0.519142 & Antrepo 32 & 1 & 1 \\
\hline Antrepo 15 & 1 & 1 & Antrepo 33 & 1 & 1 \\
\hline Antrepo 16 & 0.107737 & 0.564026 & Antrepo 34 & 1 & 1 \\
\hline Antrepo 17 & 1 & 1 & Antrepo 35 & 1 & 1 \\
\hline Antrepo 18 & 1 & 1 & & & \\
\hline
\end{tabular}

Her iki modelin sonuçları incelendiğinde antrepo 7, 9, 10, 15, 17, 18, 20, 23, 24, 25, 28, 31, 32, 33, 34 ve 35 göreli olarak etkin antrepolardır. 1, 2 ve 6 numaralı antrepolar CCR modelinde etkin olmayan antrepolar olarak değerlendirilirken, BCC modeline göre etkin antrepolar olarak ölçülmüştür. Bu da CCR modelinin daha anlamlı sonuçlar verdiğini göstermektedir.

\section{SONUÇ ve TARTIŞMA}

Uluslararası ticarette malların serbest dolaşımına aracılık eden antrepolar, lojistik faaliyetlerden özellikle depolama ve stoklama hizmetlerinde önemli görevler üstlenmektedir. Bu alanlarda muhafaza edilen eşyalar, eşyanın ülke sınırına girdiği andan serbest dolaşıma giriş işlemleri tamamlanıncaya kadar belirli bir süre uygun şartlarda depolanmaktadır. Örneğin bir eşya ithalat işlemleri tamamlanıncaya kadar bu gümrüklü alanlarda depolanmakta, elleçleme gibi lojistik faaliyetlere tabi tutulmakta veya gelen eşyanın uygun olmaması durumunda mahrece iade işlemleri bitene kadar depolanmaktadır. Faaliyetleri ve işleyişleri gümrük idarelerinin denetimi ve kontrolüne tabi olan bu işletmeler her yıl belirledikleri hedeflere ulaşmak ve belirtilen bu hizmetleri etkin sunabilmek için elindeki mevcut kaynakları optimal kullanmak zorundadır. Bu işletmelerin sahip olduğu kaynakların etkinliğinin özellikle çok kriterli karar verme yöntemleri gibi farklı yöntemler kullanarak ölçülebilmesi mümkündür. Bu ölçüm tekniklerinden birisi de veri zarflama analizidir. VZA, çoklu girdi ve çıtı değişkenlerine göre alternatifleri oluşturan karar verme birimlerinin kıyaslanmasına olanak tanıyan kullanışlı bir tekniktir.

Her çalışmada olduğu gibi bu çalışmanın da uygulama kısmında belirli kısıtlar söz konusudur. Çalışmada kısıt olarak İstanbul'da Muratbey gümrük müdürlüğüne bağlı hizmet veren A tipi antrepolar değerlendirmeye alınmıştır. 2019 yılı verilerinin elde edildiği 35 A tipi antreponun etkinliği girdi yönelimli VZA ile analize tabi tutularak değerlendirilmiştir. Uygulamada uzman görüşleri temel alınarak belirlenen ve girdi olarak kullanılan dört değişken antrepo alanı, çalışan sayısı, forklift sayısı ve transpalet sayısı'dır. Çıktı değişkenleri ise beyanname 
sayısı, tır/konteyner sayısı, elleçlenen eşya miktarı ve antrepoya kabul edilen eşya miktarı' dır. Çalışmada öncelikle 2019 yılı verilerinin elde edildiği 35 antreponun etkinliği girdi yönelimli CCR ve BCC yöntemleriyle analiz edilmiştir. Bir sonraki adımda homojen özelliğe sahip antrepoları tespit etmek için, KVB’lerini oluşturan Muratbey Gümrük Müdürlügü̈ne bağlı 35 A tipi antreponun homojenliğinin tespitinde, kümeleme analizi yönteminden hiyerarşik kümeleme tekniği kullanılmıştır. 31 antreponun homojen olduğu tespit edilmiş ve son adımda ise bu 31 antrepo için girdi yönelimli CCR ve BCC yöntemleri kullanılarak etkinlikleri yeniden değerlendirilmiştir. Her iki analiz sonucunda da antrepo 7, 9, 10, 15, 17, 18, 20, 23, 24, 25, 28, 31, 32, 33, 34 ve 35'in göreli olarak etkin antrepolar olduğu tespit edilmiştir. Göreli olarak etkin olmayan antrepolarla birlikte sıralama şu şekilde devam etmektedir: Antrepo 6, 4, 1, 19, 11, 14, 8, 13, 3, 29, 2, 22, 21, 16 ve antrepo 30.

Literatürde daha önceki çalışmalar incelendiğinde Acer ve Kalender (2020) tarafından çok kriterli karar verme yöntemleri kullanılarak yapılan çalışmada antrepoların performansı değerlendirilmiş ve sıralama yapılmıştır. Değerlendirme kriterleri olarak yıllık eşya miktarı, rampa sayısı, çalışan sayısı, ekipman sayısı, ardiye ücreti ve tasfiyelik eşya miktarı ölçütleri temel alınmıştır. Bu ölçütler ışığında kriterlerin ağırlıkları çok kriterli karar verme yöntemlerinden biri olarak Entropi yöntemi ile değerlendirmeye tabi tutulmuş ve en önemli kriterin tasfiyelik eşya olduğu bulgusu elde edilmiştir. Daha sonra bu ağırlıklar temel alınarak 40 antreponun performansı TOPSIS yöntemiyle sıralanmıştır. Yıllık antrepoya kabul edilen eşya miktarı, çalışan sayısı ve antrepoda kullanılan temel ekipmanlar kriterlerinin antrepoların operasyonel etkinliğini ve performansını etkilediği bulgusu bu çalışma ile örtüşmektedir.

Yapılan bu çalışmada Acer ve Kalender (2020)'in daha önce yapmış olduğu çalışmadan farklı olarak uzmanlar tarafından etkinlik ölçütleri belirlenmiştir. Antrepoların etkinlik değerlendirmesinde temel alınacak kriterler olduğu tespit edilen bu kriterler şunlardır: antrepo alanı, çalışan sayısı, forklift sayısı ve transpalet sayısı, beyanname sayısı, tır/konteyner sayısı, elleçlenen eşya miktarı ve antrepoya kabul edilen eşya miktarı. Bu çalışmanın bir diğer farklı tarafı ise sadece performanslara göre antrepoların sıralanmamış olmasıdır. Antrepoların operasyonel etkinliği çalışmada tartışılarak etkin olmayan antrepolar için de önerilerde bulunulmuştur.

VZA'nın diğer çok kriterli karar verme yöntemlerinden farkı, sadece sıralama yapılmasına imkan tanımaması aynı zamanda referans kümeleri de vermesidir. VZA-CCR yöntemi kullanılarak yapılan analiz sonuçlarına göre etkin olmayan fakat $0.9699^{\prime}$ luk etkinlik skoru ile sıralamada en yüksek puanı alan antrepo $6^{\prime}$ nın $\lambda^{*}=0,3520$ değeri ile antrepo 32' yi, $\lambda^{*}=0,2877$ değeri ile antrepo $28^{\prime} \mathrm{i} \quad \lambda^{*}=0,1959$ değeri ile antrepo $23^{\prime} \ddot{\mathrm{u}}, \lambda^{*}=0,1711$ değeri ile antrepo 7'yi $\lambda^{*}=0,1150$ değeri ile antrepo $10^{\prime} \mathrm{u}, \lambda^{*}=0,0906$ değeri ile antrepo $24^{\prime}$ ü ve $\lambda^{*}=0,0835$ değeri ile antrepo 25'i referans küme alması tavsiye edilmektedir. Sıralamada bir diğer yüksek etkinlik skoruna sahip olan fakat etkin olmayan antrepolardan biri olan antrepo 4, 31 antrepo içinde 18. sırada yer almaktadır. Aynı zamanda antrepo $7 \lambda^{*}=0,3271$ yoğunluk değeri, antrepo $23 \lambda^{*}=0,3213$ yoğunluk değeri, antrepo $33 \lambda^{*}=0,0958$ yoğunluk değeri, antrepo $28 \lambda^{*}=0,0842$ yoğunluk değeri ve antrepo $24 \lambda^{*}=0,0837$ yoğunluk değeri ile antrepo $4^{\prime}$ ün referans kümesini oluşturmaktadır. Sıralamada 19. sırada yer alan antrepo $1^{\prime}$ in referans kümeleri ise $\lambda^{*}=0,4511$ yoğunluk değeri ile antrepo $32, \lambda^{*}=0,3450$ yoğunluk değeri ile antrepo $10, \lambda^{*}=0,2378$ yoğunluk değeri ile antrepo $23, \lambda^{*}$ $=0,0841$ yoğunluk değeri ile antrepo 35 ve son olarak $\lambda^{*}=0,0805$ yoğunluk değeri ile antrepo $25^{\prime}$ tir.

VZA yöntemi kullanılarak antrepoların etkinliğinin değerlendirilmesiyle ilgili literatürde yer alan bir çalışma olmadığından bu çalışmanın gelecekte yapılacak çalışmalar için literature katkı sağlayacağı düşünülmektedir. Çalışmada tespit edilen bu kriterler sadece antrepoların değil, aynı zamanda depolarında performans ve etkinliğini değerlendirmede göz önünde bulundurulması gereken kriterlerdir. Bundan sonraki çalışmalarda diğer bölge müdürlüklerine bağlı antrepolar çok kriterli karar verme yöntemleri ile analize tabi tutulabilir, belirli bir bölgede faaliyet gösteren depoların da performansı ve etkinliği bu kriterlere göre değerlendirilebilir veya depoların/antrepoların performansını ve etkinliğini etkileyen kalitatif değişkenler tespit edilerek uygun parametrik olmayan yöntemlerle analiz edilebilir. 


\section{KAYNAKÇA}

Abbott, M. and Doucouliagos, C. (2003). The efficiency of Australian universities: a data envelopment analysis. Economics of Education review, 22(1), 89-97.

Acer, A. ve Kalender, S. (2020). Antrepoların performansının entropi ve TOPSIS yöntemiyle değerlendirilmesi. Dumlupınar Üniversitesi Sosyal Bilimler Dergisi, (65), 1-20.

Arlı, E. (2009). Uluslararası fiziksel dağıtımda antrepo sahipliğinin ihracat yapan işletmelerin performansına etkileri, Kocaeli Üniversitesi S.B.E. Doktora Tezi.

Bal, V. (2013). Vakıf üniversitelerinde veri zarflama analizi ile etkinlik belirlenmesi. Manas Sosyal Araştırmalar Dergisi, 2(1), 1-20.

Banker, R. D., Charnes, A. and Cooper, W.W. (1984). Some models for estimating technical and scale inefficiencies in data envelopment analysis", Management Science, 30 (9), pp. 1078-1092.

Banker, R. D., Cooper, W. W., Seiford, L. M. and Zhu, J. (2011). Returns to scale in DEA. In Handbook on data envelopment analysis (pp. 41-70). Springer, Boston, MA.

Bayat, T. ve Özdemir, Ş. (2019). Ulaştırma altyapısının bölgesel bazli lojistik sektörü üzerindeki etkinliğinin veri zarflama yöntemi ile ölçülmesi. Kırıkkale Üniversitesi Sosyal Bilimler Dergisi, 9(2), 259-286.

Baysal, M., Alçılar, B., Çerçioğlu, H. ve Toklu, B. (2005). Türkiye'deki devlet üniversitelerinin 2004 yılı performanslarının, veri zarflama analizi yöntemiyle belirlenip buna göre 2005 yılı bütçe tahsislerinin yapılması. Sakarya Üniversitesi Fen Bilimleri Enstitüsü Dergisi, 9(1), 67-73.

Behdioğlu, S. ve Özcan, A. G. G. (2009). Veri Zarflama Analizi ve Bankacilik Sektöründe Bir Uygulama. Süleyman Demirel Üniversitesi İktisadi ve İdari Bilimler Fakültesi Dergisi, 14(3), 301-326.

Boussofiane, A., Dyson, R. G. and Thanassoulis, E. (1991). Applied data envelopment analysis, European Journal of Operational Research, 52(1), 1-15.

Budak, H. (2011). Veri zarflama analizi ve Türk bankacılık sektöründe uygulaması. Marmara Fen Bilimleri Dergisi, 23(3), 95-110.

Çağlar, V. (2012). Türk Özel Limanlarının Etkinlik ve Verimlilik Analizi, Dokuz Eylül Yayınları.

Chen, T. Y., Chen, C. B. and Peng, S. Y. (2008). Firm operation performance analysis using data envelopment analysis and balanced scorecard. International Journal of Productivity and Performance Management.

Cook, W. D. and Zhu, J. (2006). Modeling Performance Measurement: Applications and Implementation Issues in $D E A$ (Vol. 566). Springer Science \& Business Media

Cooper, W.W., Seiford, L.M. and Zhu, J. (2011). Data Envelopment Analysis: History, Models, and Interpretations, Cooper, W.W., Seiford L.M. and Zhu J. (ed.), Handbook on Data Envelopment Analysis, USA: Springer Science+Business Media, 1-39

Cullinane, K. \& Wang, T. F. (2007). Data Envelopment Analysis (DEA) and Improving Container Port Efficiency. Research in Transportation Economics, 17, 517-566.

Demirci, A. ve Tarhan, D. B. (2017). Karayolu taşımacılığı optimizasyonu: veri zarflama analizi ile mersin ilinde bir uygulama. Toros Üniversitesi İISBF Sosyal Bilimler Dergisi, 4(7), 112-131.

Düzakın, E. ve Düzakın, H. (2007). Measuring the performance of manufacturing firms with super slacks based model of data envelopment analysis: An application of 500 major industrial enterprises in Turkey. European Journal of Operational Research, 182(3), 1412-1432.

Dyson, R. G., Allen, R., Camanho, A. S., Podinovski, V. V., Sarrico, C. S. and Shale, E. A. (2001). Pitfalls and protocols in DEA. European Journal of Operational Research, 132(2), 245-259.

Easton, L., Murphy, D. J. and Pearson, J. N. (2002). Purchasing performance evaluation: with data envelopment analysis. European Journal of Purchasing \& Supply Management, 8(3), 123-134.

Ersoy, Y. ve Tehci, A. Lojistik Pazarlama: Lojistik hizmetleri alanında faaliyette bulunan işletmelerde veri zarflama analizi ile etkinlik ölçümü. The Journal of International Scientific Researches, 5(1), 1-9. 
Farrel, J. (1957). The Measurement of Productive Efficiency. Journal of the Royal Statistical Society. Series A, General 125. Part, (2), 252.

Göktolga, Z., \& Artut, A. (2014). İktisadi ve İdari Bilimler Fakülteleri'nin Bulanık Veri Zarflama Analizi ile Verimlilik Ölçümü. Cumhuriyet Üniversitesi İktisadi ve İdari Bilimler Dergisi, 15(1), 55-75.

Gülsevin, G., \& Türkan, A. H. (2012). Afyonkarahisar hastanelerinin etkinliklerinin veri zarflama analizi ile değerlendirilmesi. Afyon Kocatepe Üniversitesi Fen ve Mühendislik Bilimleri Dergisi, 12(2), 1-8.

Henriques, I. C., Sobreiro, V. A., Kimura, H. and Mariano, E. B. (2018). Efficiency in the Brazilian banking system using data envelopment analysis. Future Business Journal, 4(2), 157-178.

Jablonsky, J. (2016), Ranking models in data envelopment analysis, Business Trends, 6(4), 36-42.

Jacobs, R. (2001). Alternative methods to examine hospital efficiency: data envelopment analysis and stochastic frontier analysis. Health care management science, 4(2), 103-115.

Kalaycı, Ş. (2010). SPSS uygulamalı çok değişkenli istatistik teknikleri (Vol. 5). Ankara, Asil Yayın Dağıtım.

Koban, E. ve Keser, H. Y. (2007). Dış Ticarette Lojistik, Ankara, Ekin Basım Yayın Dağıtım

Kohl, S., Schoenfelder, J., Fügener, A. and Brunner, J. O. (2019). The use of data envelopment analysis (DEA) in healthcare with a focus on hospitals. Health care management science, 22(2), 245-286.

Kutlar, A. ve Kartal, M. (2004). Cumhuriyet üniversitesinin verimlilik analizi: fakülteler düzeyinde veri zarflama yöntemiyle bir uygulama. Kocaeli Üniversitesi Sosyal Bilimler Dergisi, (8), 49-79.

Lojistiğin Tanımı, https://cscmp.org/ (Erişim Tarihi:18.09.2020)

Markovits-Somogyi, R., Gecse, G. and Bokor, Z. (2011). Basic efficiency measurement of Hungarian logistics centres using data envelopment analysis. Periodica Polytechnica Social and Management Sciences, 19(2), 97-101.

Min, H. and Joo, S. J. (2006), Benchmarking the operational efficiency of thirdparty logistics using data envelopment Analysis, Supply Chain Management, 11(3), 259-265.

Motroi, A. (2018), İmalat işletmelerinde veri zarflama analizi ile verimlilik ölçümü, Bankacılık ve Finansal Araştırmalar Dergisi, 5,1 .

Nayar, P. and Ozcan, Y. A. (2008). Data envelopment analysis comparison of hospital efficiency and quality. Journal of medical systems, 32(3), 193-199.

Önsoy, E. (2013). Veri Zarflama analizi kullanılarak kargo şirketlerinin performanslarının değerlendirilmesi, Gazi Üniversitesi Fen Bilimleri Enstitüsü Yüksek Lisans Tezi, Ankara).

Oum, T.H. and Yu, C. (2004), Economic efficiency of railways and implications for public policy: A comparative study of the OECD countries railways, Journal of Transport Economics and Policy, 28(2), 21-38.

Özden, Ü. (2008). Veri zarflama analizi (VZA) ile Türkiye'deki vakıf üniversitelerinin etkinliğinin ölçülmesi. İstanbul Üniversitesi İşletme Fakültesi Dergisi, 37(2), 167-185.

Paradi, J. C. and Zhu, H. (2013). A survey on bank branch efficiency and performance research with data envelopment analysis. Omega, 41(1), 61-79.

Perçin, S. ve Çakır, S. (2012). Demiryollarında süper etkinlik ölçümü: Türkiye örneği. Dokuz Eylül Üniversitesi İktisadi ve İdari Bilimler Fakültesi Dergisi, Cilt:27, Sayı:1, 29-45.

Petekkaya, Ş. (2018). Türkiye'deki serbest bölgelerin veri zarflama analizi ile performanslarının değerlendirilmesi. Bulletin of Economic Theory and Analysis, 3(2), 109-134.

Ramanathan, R. (2003). An Introduction to Data Envelopment Analysis: A Tool for Performance Measurement, Sage Publications

Santos, S. P. and Amado, C. A. (2014). On the need for reform of the Portuguese judicial system-Does data envelopment analysis assessment support it? Omega, 47, 1-16.

Sarı, V.İ. (2010). Proje Döngüsü Yönetiminde Etkililik Değerlendirmesi, Ankara, DPT Uzmanlık Tezleri Bölgesel Gelişme ve Yapısal Uyum Genel Müdürlügü, 


\section{A. Acer 13/4 (2021) 2976-2989}

Sarrico, C. S., Hogan, S. M., Dyson, R. G. and Athanassopoulos, A. D. (1997). Data envelopment analysis and university selection. Journal of the operational research society, 48(12), 1163-1177.

Savaş, F. (2015). Veri Zarflama Analizi. Yıldırım, F.B. \& Önder, E (Ed.), Çok kriterli karar verme yöntemleri, Bursa, Dora Yayınları, 2. Bask1.

Seyrek, İ. H. ve Ata, H. A. (2010). Veri zarflama analizi ve veri madenciliği ile mevduat bankalarında etkinlik ölçümü. BDDK Bankacılık ve Finansal Piyasalar Dergisi, 4(2), 67-84.

Shapiro, R. D. and Heskett J. L. (1985). Logistic Strategy, Minnesota, West Publishing Company.

T.C. Yasalar (27.10.1999). 4458 sayılı Gümrük kanunu. Ankara: Resmi Gazete (23866 sayılı). Gümrük yönetmeliği,

Tanyaş, M. ve Baskak, M. (2012). Farklı açılardan depoların sınıflandırması. Ulusal Lojistik ve Tedarik Zinciri Kongresi, Konya.

Tetik, S. (2003). İşletme performansını belirlemede veri zarflama analizi, Yönetim ve Ekonomi: Celal Bayar Üniversitesi İktisadi ve İdari Bilimler Fakültesi Dergisi, 10(2), 221-230.

Thanassoulis, E. (1999). Data envelopment analysis and its use in banking. Interfaces, 29(3), 1-13.

Tonanont, A., Yimsiri, S., Jitpitaklert, W. and Rogers, K. J. (2008). Performance evaluation in reverse logistics with data envelopment analysis. In IIE Annual Conference. Proceedings (p. 764).

Torabipour, A., Najarzadeh, M., Mohammad, A. R. A. B., Farzianpour, F. and Ghasemzadeh, R. (2014). Hospitals productivity measurement using data envelopment analysis technique.Iranian journal of public health, 43(11).

Türkiye Cumhuriyeti Ticaret Bakanlığı, Antrepo Sayıları https://ticaret.gov.tr/istatistikler/bakanlikistatistikleri/gumruk-istatistikleri/tasfiye-verileri, (Erişim Tarihi: 12.01.2021).

Ulucan, A. (2002). İSO 500 şirketlerinin etkinliklerinin ölçülmesinde veri zarflama analizi: Farklı girdi çıtı bileşenleri ve ölçeğe göre getiri yaklaşımları ile değerlendirmeler. Ankara üniversitesi SBF dergisi, 57(02).

Ustall, N. K. ve Tosun, Ö. (2020). Investigation of logistic performance of G-20 countries using data envelopment analysis and malmquist total factor productivity analysis. Mehmet Akif Ersoy Üniversitesi İktisadi ve İdari Bilimler Fakültesi Dergisi, 7(3), 755-781.

Wang, T. F., Cullinane, K., and Song, D. W. (2003). Container port production efficiency: A comparative study of DEA and FDH approaches, Journal of The Eastern Asia Society for Transportation Studies, 5, 698-701.

Waters, D (2003). Logistics: An Introduction to Supply Chain Management, Palgrave Macmillan.

Yeung, L. L. and Azevedo, P. F. (2011). Measuring efficiency of Brazilian courts with data envelopment analysis (DEA). IMA Journal of Management Mathematics, 22(4), 343-356.

Yıldırım, M. ve Ayvaz, B. (2019). Ülkelerin lojistik performanslarinin veri zarflama analizi ile ölçümü. İstanbul Ticaret Üniversitesi Fen Bilimleri Dergisi, 18(35), 57-73.

Zhang, S., Lundgren, T. and Zhou, W. (2016). Energy efficiency in Swedish industry: A firm-level data envelopment analysis. Energy Economics, 55, 42-51. 